\title{
AGAINST THE DISCARDED-CREATED DISTINCTION IN EMBRYONIC STEM CELL RESEARCH
}

\author{
Katrien Devolder
}

\section{THE DILEMMA}

Most of the ethical debate about whether we should support human embryonic stem cell (hESC) research turns on a fundamental disagreement about how we should treat early human embryos. As it is currently done, the isolation of human embryonic stem cells (hESCs) involves dismantling the early human embryo - a process the embryo does not survive. Many people accord significant value to the human embryo (henceforth 'embryo') and think that embryos may not simply be used in whatever way suits our research interests. However, hESC research holds unique promise for developing therapies for currently incurable diseases, as well as for important biomedical research and drug and toxicity testing. This creates a dilemma: either one supports hESC research and accepts resulting embryo destruction, or one opposes hESC research and accepts that its potential benefits will be foregone.

Of course, for some people there is no dilemma. If you believe an early human embryo is merely a collection of cells that has very little value in itself, the embryo's moral status provides no reason to abstain from hESC research. On the other hand, if you believe that the embryo has the same moral status as a typical adult human, then isolating hESCs is equivalent to murder and is clearly unjustified. But for those who accord lesser but still significant moral status to the embryo, the dilemma is very real.

A popular response to the dilemma has been to adopt some intermediate position between the dominant opposed ethical views that the moral status of the embryo always and never gives us decisive reasons to abstain from hESC research. One such intermediate position that has been widely defended and that serves as a basis for stem cell policy in many western countries, including the US under the Obama administration, is the so-called 'discarded-created distinction'.[1]

\section{THE DISCARDED-CREATED DISTINCTION}

The discarded-created distinction draws a moral line between two types of hESCs based on their origin: embryos discarded following in vitro fertilisation (IVF) and embryos created solely for the purpose of stem cell research.

Discarded-created distinction: It is ethically permissible to derive and use hESCs from discarded IVF embryos. It is ethically impermissible to create embryos solely for the purpose of stem cell derivation, and to derive or use hESCs from such embryos. 


\section{Discarded Embryos}

The great majority of currently existing hESC lines originate from embryos discarded following IVF. A woman undergoing IVF receives hormone therapy to stimulate the development and maturation of multiple eggs. After retrieval, the eggs are fertilised with semen in culture media. In most countries where IVF is practised, on average five to ten embryos are produced, one or two of which will be transferred to the woman's womb to try to achieve a pregnancy. The remaining embryos are placed in nitrogen freezers, were they are cryopreserved. If an attempt to achieve a pregnancy fails, one or two embryos can be thawed for another attempt. Cryopreservation of several embryos has the advantage that women do not have to undergo the risky and uncomfortable hormone therapy and egg retrieval procedure after each failed attempt to generate a pregnancy.

At the start of their IVF treatment, individuals or couples must indicate one of the following three options for handling of any leftover embryos, that is, embryos unwanted by the individual or couple: (1) anonymous donation to infertile couples, (2) donation to scientific research, or (3) letting the embryos perish. ${ }^{1}$ Note that the two last options both involve certain death for the embryos with no opportunity to develop into a child. The great majority of existing hESC lines are obtained from leftover IVF embryos donated for research - as under option (2). I will refer to such embryos as discarded IVF embryos.

\section{Created Embryos}

There is an alternative source of hESCs. The cells could be derived from embryos especially created for the purpose of research. I will refer to such embryos as 'research embryos' (the term 'created' in the discarded-created distinction is somewhat confusing as IVF embryos are created too, just for a different purpose). One way to generate research embryos is through IVF using donor gametes. In some countries stem cell scientists have encountered difficulties to achieve their intended research goals because the number of discarded IVF embryos available for stem cell research is insufficient. Creating research embryos using IVF (with no reproductive intent) could solve this problem and would allow these researchers to achieve their research goals more efficiently. But research embryos would, in the future, most likely be generated using cloning or somatic cell nuclear transfer (SCNT). SCNT involves transferring the nucleus of a somatic cell into an oocyte from which the nucleus, and thus most of the genetic material, has been removed. The manipulated oocyte is then treated, usually with an electric current, in order to stimulate cell division, and an embryo is formed. A significant advantage of using stem cells from embryos produced through SCNT rather than those derived from discarded IVF embryos is that the hESCs would be genetically identical to the person from whom the somatic cell nucleus was taken, perhaps a patient. One goal of stem cell research is the development of stem cell-based therapies. Embryonic stem cells could be used to generate an inexhaustible supply of replacement cells to regenerate damaged tissues and organs. The advantage of using hESCs that are genetically identical to the patient is that the cells or tissues produced from these stem cells

1 These three options are presented in most countries where IVF is practised. Some countries, however, only offer one or two of these options, or none. In Brazil, for example, couples can only opt for indefinite cryopreservation. 
would not be rejected by the patient's immune system. This is significant, as one of the major problems in transplantation medicine is immunorejection of the graft. Unfortunately, these therapies are not yet on the horizon. First, a great deal of research is required, including research with embryos created through SCNT.(First of all, researchers will have to learn how to routinely produce such embryos and how to derive stem cells from them).

Embryonic stem cells genetically identical to the patient could also be used to study diseases in vitro. Researchers could create large numbers of stem cells genetically identical to the patient and then experiment on these in order to understand the particular features of the disease in that person. The increased possibility to study disease in a dish would enable research that cannot be done in patients themselves or where there are too few patients to work with as in the case of rare genetic diseases. Stem cells genetically identical to a patient would also be of great value for drug screening and toxicity testing. For example, hepatocytes (liver cells) derived from stem cells that were obtained from embryos genetically identical to patients with various genetic and disease backgrounds could be used for predicting the liver toxicity of candidate drug therapies.

Thus, using embryos created through SCNT can help us achieve research and therapeutic aims that would be much more difficult or perhaps impossible to achieve using discarded IVF embryos. However, embryos created using SCNT are research embryos - they are created solely for the purpose of research. According to the discarded-created distinction, using (and thus destroying) research embryos is ethically unacceptable, even to achieve the aforementioned promising research and therapeutic aims. Since many countries have based their stem cell regulations on the discarded-created distinction, research using SCNT embryos has been severely restricted worldwide.

The question then is why we should we forego the benefits of research on embryos created especially for the purpose of research, be it by using SCNT or IVF (without reproductive intent)? Why is the destruction of research embryos to obtain stem cells less acceptable than the destruction of discarded IVF embryos, and to such an extent that the latter should be supported but the former rejected?

I start by investigating how proponents of the discarded-created distinction justify the destruction of discarded IVF embryos to obtain stem cells even if embryos have significant moral status. I show that the justification for destroying discarded IVF embryos also applies, at least at first sight, to the destruction of research embryos. This suggests that there should be a presumption against the discarded-created distinction. I then consider whether this presumption can be overridden. After exploring the main arguments in support of the discarded-created distinction, I conclude that, none of these arguments hold and that, consequently, we should reject the discarded-created distinction as an ethical position.

But first, let us consider how proponents of the discarded-created distinction justify the destruction of discarded IVF embryos, even if embryos have significant moral status. 


\section{ARGUMENTS FOR USING DISCARDED IVF EMBRYOS}

\section{Beneficence and Nonmaleficence}

Human embryonic stem cell research could, if successful, benefit hundreds of thousands of people. It could not only save and prolong lives, but also considerably reduce morbidity. Failing to pursue this research could result in many avoidable deaths, and in more suffering in general. It is widely accepted that we have significant reasons to benefit people if we can and to prevent avoidable suffering and death. There are thus significant reasons of beneficence and nonmaleficence for pursuing hESC research. Proponents of the discardedcreated distinction have appealed to these arguments to justify destroying discarded IVF embryos in stem cell research.[1,2]

\section{Proportionality}

Even if one thinks that reasons of beneficence and nonmaleficence are strong reasons for pursuing hESC research one may still think that these reasons are not strong enough to outweigh the countervailing reasons not to destroy embryos. Which reasons prevail will depend, at least in part, on how great the benefits of hESC research are relative to the moral costs of embryo destruction. Proponents of the discarded-created distinction evidently believe that the benefits are large enough, relative to the costs, to justify the destruction of discarded IVF embryos in stem cell research. This is sometimes made explicit. For example, in its recommendations on stem cell research, the US National Bioethics Advisory Commission (NBAC) (p. 52), defending the discarded-created distinction, wrote: "In our view, the potential benefits of the research outweigh the harms to the embryos that are destroyed in the research process".[1] The obvious question that arises, then, is: if the benefits of hESC research are sufficient to outweigh the moral costs of destroying discarded IVF embryos, why do the same benefits not outweigh the costs of destroying research embryos? At first sight, the benefits that justify the destruction of discarded IVF embryos could also justify the destruction of research embryos. The benefits are of the same kind, and potentially, equally large. Moreover, most people would agree that the moral status of discarded IVF embryos is equal to that of research embryos. This suggests there should be a presumption in favour of treating research and discarded IVF embryos similarly - a presumption against the discarded-created distinction. I now turn to consider how one might nevertheless defend the discarded-created distinction by appealing to arguments that may override this presumption.

\section{ARGUMENTS FOR THE DISCARDED-CREATED DISTINCTION}

\section{The Least Controversial Approach}

An initial argument holds that, even if the benefits of hESC research outweigh both the use of discarded IVF embryos and the use of research embryos, we should only use discarded IVF embryos because, if we have different means for achieving the intended goals, we should always opt for the least controversial or the least offensive approach.[3] 
However, it is not true that we can achieve our intended research goals by using only discarded IVF embryos. As mentioned earlier, some research (and therapeutic) goals can only be achieved using research embryos. Furthermore, determining what approach is the least controversial is of course controversial itself and will partly depend on who decides what is most controversial and on how well people are informed about the variety of issues raised by different types of stem cell research. It seems that in the stem cell debate it has been assumed too quickly that respect for the embryo is the only relevant or the most important consideration for determining how controversial certain means for obtaining stem cells are. But other considerations, that have been brought less to the attention, may also need to be taken into account, such as whether alternative means will slow down the research, what risks they involve to patients, what the economic costs will be, and so forth. [4] For example, obtaining neuronal stem cells from patients through brain biopsy does not involve embryo destruction but may impose a significant risk to the patient and may, therefore, be more controversial than using stem cells from research embryos. Moreover, some may think that embryos created through SCNT have lower moral status than discarded IVF embryos and that it is therefore less controversial to use SCNT embryos to obtain stem cells. It has, for example, been argued that SCNT embryos have lower moral status because they lack the potential to develop into a baby (this is not yet technically possible) or because according them moral status on the basis of their potential would result in a reductio ad absurdum as, in McHugh's words, "then every somatic cell would deserve some protection because it has the potential to follow the same path".[5]

Stating that we should reject the use of research embryos simply because it is more controversial than using discarded IVF embryos not only assumes too quickly that both means will enable us to achieve the same research goals, but also begs the question. That using stem cells from research embryos is the most controversial approach is exactly what needs to be argued for.

That leaves us with our initial question: why is it so much worse to use research embryos than to use discarded IVF embryos?

\section{The Nothing-Is-Lost Argument}

The most important argument in defence of the discarded-created distinction is the nothingis-lost argument (sometimes also referred to as the no-greater-loss argument[6]). This argument was introduced by Paul Ramsey in the debate about the ethics of direct killing.[7] Ramsey argued that intentionally killing innocent human life is always wrong except when two conditions are met: (1) the innocent will die soon in any case, and (2) other innocent life will be saved. In Bernard Williams' famous case 'Jim and the Indians'[9], Jim faces such a situation. Jim arrives in a South American town where twenty Indians are just about to be killed by a group of soldiers. The captain makes an offer: if Jim kills one Indian, the others will be let off. If Jim refuses the offer, the captain will do what he would do had Jim not arrived: kill the twenty Indians. Jim's killing of one Indian may be justified by the nothingis-lost argument: the one Indian would have died soon in any case and the other Indians will be saved. 
The nothing-is-lost argument has been extended to the stem cell debate.[4, 9, 10] It has been argued that, since (1) discarded IVF embryos (innocent life) will die soon in any case and (2) patients suffering from terrible diseases and disabilities (other innocent life) will be saved, it is permissible to destroy discarded IVF embryos to derive stem cells: it will not change their final disposition (death in the early embryonic stage) and will thus not cause a greater loss than would otherwise occur.

It has further been argued that the nothing-is-lost argument cannot be extended to the derivation of stem cells from research embryos. According to Gene Outka, a committed defender of the discarded-created distinction, "we would distort the nothing is lost principle beyond recognition if we extended it to say that nothing is lost when we create an entity whose prospects are nil because of what we intend from the start."[7] (p. 598). For the nothing-is-lost argument to be applicable, it is at least required "that we encounter circumstances we did not initiate and that we wish were otherwise."[7] (p. 596).

So it seems that for the nothing-is-lost argument to be applicable, one should not have initiated the circumstances which ensure that the loss will occur in any case, and if these circumstances obtain, one should wish they did not.

\section{Initiating circumstances ensuring that the loss would occur in any case}

In what sense does a researcher who derives stem cells from a research embryo initiate the circumstances ensuring that the loss would occur in any case? (Note that the 'loss' must be the fact that the embryo dies, as it is the fact that discarded IVF embryos will die in any case which, according to defenders of the discarded-created distinction, justifies extending the nothing-is-lost argument to the destruction of discarded IVF embryos).

It cannot be that the researcher ensured that the embryo would die anyway by creating the embryo for the purpose of research, as the researcher who destroys the embryo does not necessarily have to be the one who created it. Yet, according to defenders of the discardedcreated distinction, the researcher who 'merely' destroys an embryo created by another researcher cannot appeal to the nothing-is-lost argument either. Moreover, since it is not the creation of the research embryo which causes the certain death of the embryo, it cannot just be its creation which will cause the loss to occur anyway.

Perhaps a better candidate is the fact that the researcher who destroys the embryo requested the creation of the embryo in the first place. Through this request, the researcher initiated the creation of the embryo in circumstances in which the embryo was certainly going to be used for research and not for reproduction. This would be enough to rule out the nothingis-lost argument as a justification for performing research on embryos whose creation one requested. However, not all those deriving stem cells from research embryos may have requested the creation of the particular embryo they are deriving stem cells from. So it must be something other than the request to create a particular embryo that makes that the embryo is bound to die from the start. 
How, then, can we justify Outka's claim that any researcher deriving stem cells from a research embryo has initiated the circumstances ensuring that the loss would occur anyway? I think there is only one plausible justification. Such a researcher is typically part of an organised group of stem cell researchers whose shared intentions, agreements, and commitments make it the case that each embryo created for research will effectively be used for research, or at least will not have any prospect of survival. For there to be any prospect of survival, stem cell researchers would have to abstain from conducting research on the embryo, the embryo would need to have the biological potential to develop into a baby, and women would need to volunteer to carry the embryos to term. Given the commitments of the stem cell researchers, the fact that SCNT embryos do not possess the potential to become a baby at the moment, and the burden on women to carry embryos to term, this is extremely unlikely to happen. By being part of a particular group of stem cell researchers committed to research on stem cells from research embryos, the researchers conducting such research are part of the group collectively responsible for the creation of this embryo in circumstances that ruled out its survival. If the researcher suddenly abstained from the derivation of stem cells from this embryo, it would not be saved. It would either be used by another researcher, or would perish. It would die anyway. But the researcher cannot appeal to this fact to justify killing the embryo. After all, she is part of a group that initiated the circumstances which ensure that this loss will occur. She shares responsibility for the embryo's inevitable death.

To clarify why the nothing-is-lost argument is not credible in a situation where one is partly responsible for the loss to occur anyway, consider a scenario in which Josef Mengele had attempted to justify his evil deeds by saying: "well, Jews were going to be gassed anyway, so it was better to conduct fatal experiments on them that could potentially save other innocent lives; it didn't change their final disposition - premature death - so nothing was lost!" Indeed, part of the problem here is that Mengele, by being a Nazi, was partly responsible for the fact that these prisoners were bound to die anyway.

To illustrate with another example - one that is more analogous to the use of research embryos - suppose I work in an animal farm. My job is to breed and provide animals to my colleagues, who will then slaughter them for meat. It is plausible that to justify the slaughtering, my colleagues cannot appeal to the fact that the animals were going to die anyway. By being part of an organised group of people that provides and slaughters animals, the person who slaughters the animal is partly responsible for the fact that the animal existed in circumstances that made it virtually impossible for the animal to escape its destiny: being slaughtered.

So where does this leave us?

It seems that the nothing-is-lost argument cannot apply when one has initiated the circumstances which ensure that the loss will occur anyway, or is part of a group that is collectively responsible for having initiated these circumstances. By being part of a group enabling the creation of embryos whose only prospect is to die in research, one helps to 
initiate the circumstances which ensure that the loss - the death of the embryos - will occur anyway.

It has been argued that by deriving stem cells from discarded IVF embryos one is not responsible in any way for the circumstances ensuring that the loss will occur anyway. Such embryos exist, and are condemned to death, because they are created to spare women from further egg harvesting and are unwanted for reproduction. Their existence is entirely separate from their use in stem cell research[11] and it is therefore perfectly consistent, according to defenders of the discarded-created distinction to accept the use and derivation of stem cells from discarded IVF embryos on the grounds that nothing is lost, while rejecting IVF practices that are responsible for the loss that would occur anyway.[7]

Initiating circumstances ensuring that future losses will occur in any case

This cannot be the whole story, however. According to the discarded-created distinction, it is impermissible to use stem cells from research embryos, even when those embryos were created by researchers with whom one has no close connection, for example, stem cell researchers abroad who routinely create research embryos and derive stem cells from these embryos for their own research. It would be difficult to argue that those who use stem cells that were derived from such embryos are partly responsible for the fact that these particular embryos were going to die anyway. So why does the nothing-is-lost argument not justify using stem cells in such cases?

At this point, the proponent of the discarded-created distinction could argue that, although using stem cells from research embryos that were not destroyed on request by the one who uses the stem cells, need not have initiated the circumstances ensuring that the embryo would have died anyway, it does contribute to such circumstances for future research embryos. After all, by using these stem cells one creates a demand for more research embryos and their stem cells, thereby initiating their existence in circumstances that close off any destination for the embryo but death. Even if the demand is not significant, and perhaps doesn't have a major impact on the number of research embryos created, by using stem cells from research embryos each stem cell researcher contributes somewhat to further creation and destruction of research embryos.

So perhaps another reason why the nothing-is-lost argument may not apply is that, although one does not at all contribute to the circumstances ensuring that the loss would occur anyway in the case in question, one contributes to such circumstances in the future. One is partly responsible for the fact that something is lost that would not have been lost otherwise. That something is not the life of the embryo from which the stem cells one is using were derived, it is the life of some future embryo.

Let us grant that this appeal to (circumstances ensuring) future embryo deaths can explain why something is lost in the case of the use of stem cells from research embryos. The question now arises whether a similar argument can be used to show that something is also lost when one performs research on stem cells from discarded IVF embryos. Adherents of the discarded-created distinction must deny this. 
They have attempted to do this by arguing that using stem cells from discarded IVF embryos does not create a demand for such embryos. Such embryos exist not for stem cell research but to protect women from the harms associated with egg harvesting. Thus discarded IVF embryos exist and will continue to exist on a large scale regardless of whether hESC research continues. The situation has been compared with that in the 'murder victim case':[12]

Murder victim case: A teen has been murdered in gang violence. After having obtained the consent of the teen's parents, a surgeon uses the murder victim's organs for transplantation into a patient who requires them in order to survive.

The surgeon is not in any way responsible for the loss (the death of the teen). It is also extremely unlikely that the surgeon, by using the organ, will be responsible for similar future losses (more gang murders). Thus, not only is nothing lost by the murder victim, no loss is caused to anyone else either. Moreover, someone will be saved. It seems that the surgeon's actions are ethically acceptable for the reason that nothing is lost. If using discarded IVF embryos to obtain stem cells is similar to using murder victims for their organs, then we should judge that it, too, is acceptable for the reason that nothing is lost, even if we believe embryos have significant moral status or the same status as a typical adult human.

But is the Murder Victim Case analogous to the use and derivation of stem cells from discarded IVF embryos? If not, we cannot just infer from the comparison that nothing will be lost by using and deriving stem cells from discarded IVF embryos. In the following subsection I argue that destructive research on IVF embryos is dis-analogous to the Murder Victim Case and in such a way that it cannot be justified by appeal to the nothing-is-lost argument. Thus, I will argue that, just as something is lost in the case of the use of stem cells from research embryos, so too it is lost in the case of the use and derivation of stem cells from discarded IVF embryos.

\section{Something Will Be Lost}

\section{First disanalogy}

One apparent difference between performing destructive research on discarded IVF embryos and the murder victim case is that, in the former case, it is the stem cell researcher who kills the embryo whereas in the murder victim case it is the gang, not the surgeon, who killed the teen. However, some have denied this difference and have argued that it is the parents who decide to donate their IVF embryo for research who kill it; the researcher only determines the manner in which it is killed, which is irrelevant as early embryos cannot experience pain.[12]

It seems, however, hard to deny that the researcher at least shares responsibility in killing the embryo. That there are embryos left over after IVF treatment is one thing, the decision to use and destroy these embryos in research is another. Dan Brock has argued that this is why what he calls the 'strong version' of the nothing-is-lost argument, which appeals to the 
fact that the loss is going to occur anyway whatever one does, cannot apply to the destruction of discarded IVF embryos.[13] Discarded IVF embryos are frozen but still alive and retain the biological potential to develop into a baby. That the embryos are going to die soon in any case is thus not true. It is the decision to use these embryos for research that removes their biological potential, as well as any chance that it will be realised. Thus, there is a loss when one destroys a discarded IVF embryo.

One reply could be that, although it is true that the discarded IVF embryo is not dead but frozen, the difference is unimportant. If discarded embryos are not destroyed in research, they will instead be eternally stored in nitrogen freezers and nothing will be lost by denying embryos a life in these freezers.[6] This is what Brock refers to as the 'weaker version' of the nothing-is-lost argument. It looks at what will happen to the embryo given what people will in fact do, not what they could do. Indeed, these frozen embryos will not in fact be used for reproductive purposes, so, in this sense, nothing will be lost by using them for research. But Brock argues that although the weaker version of the nothing-is-lost argument applies to the destruction of discarded IVF embryos, it shouldn't be accepted by those who think the embryo has significant moral status. Accepting that nothing is lost because the embryo will not be 'rescued' by anyone anyway is like accepting killing an abandoned baby for its organs with the argument that it was going to die anyway. The right response is to do whatever one could do to save the baby or, for that matter, the embryo.

However, the defender of the discarded-created distinction could still object that although it is true that these embryos have the potential to live and could be rescued, it is not feasible to rescue all of them given the realities of IVF practices in many countries. In the US alone, about 400,000 embryos are stored in freezers. Nightlight Christian Adoption's 'Snowflakes program' has arranged adoptions of some of these embryos but despite their efforts to 'rescue' frozen embryos, the great majority will be discarded. So adherents of the discardedcreated distinction may argue that, although in an ideal world they would save all frozen embryos, or prevent their existence, this is not possible now. They can then argue that if we cannot save the hundreds of thousands frozen embryos worldwide, we should not let them go to waste but should use them for beneficial research. Nothing will be lost.

So even though it is true that the embryos have the biological potential to become babies, if this potential cannot be realised even if one does whatever one can to realise it, then perhaps nothing important is lost by depriving them of that potential by destroying them in research.

Thus, while it is true that stem cell researchers actually kill discarded embryos, whereas the transplant surgeon does not kill the teen, it seems doubtful that this difference is morally significant. The stem cell researchers do deprive the embryos of potential, but it is not clear that this is important given that the potential was extremely unlikely to be realised, despite efforts to do so.

Second disanalogy 
There is, however, another difference between the Murder victim case and the use of discarded IVF embryos in stem cell research - a difference that is more clearly significant. In discussing whether the use of tissue from aborted foetuses is analogous to the use of organs from murder victims, Lynn Gillam distinguishes three mechanisms by which using the murder victim's organs might result in more murders: (1) by changing society's moral beliefs about murder, (2) by decreasing the state's efforts to deter it, and (3) by strengthening incentives to commit murder.[14] She suggests that, because condemnation of murder is so deep-rooted in our moral psyche and is strongly reinforced by law worldwide, it is very unlikely that any of these effects will occur if we use organs from murder victims; it is therefore ethically acceptable to do this. But the circumstances of abortion differ from those of criminal murder: Condemnation of abortion is not deeplyrooted in almost everyone's intuitions, abortion legislation differs from country to country and has changed over time, and abortion is generally performed by the medical profession within a regulatory framework. These circumstances make it more likely that lobbying from pro-choice groups and the potential benefits of fetal tissue research will provide an incentive to relax existing abortion regulation or will result in reduced efforts to prevent abortion. In such a climate it may also be easier for women to justify their decision to abort their foetus. Gillam's point is that the differences in circumstances between abortion and criminal murder make it more likely that fetal tissue research will result in an increase in the number of abortions performed than that transplantation from murder victims will increase the murder rate.

Gillam's reasoning also applies to hESC research as the circumstances are very similar to those of fetal tissue research.[15] Using discarded IVF embryos can, through mechanisms similar to those described by Gillam, indirectly promote embryo destruction. For example, the benefits of hESC research may weaken efforts to reduce the number of embryos discarded in IVF. Although a society that accepts IVF will not suddenly stop offering IVF treatments, it might still change the practice in such a way that fewer surplus embryos are created, and thus fewer embryos will die. By routinely using discarded IVF embryos in research, one removes the incentive to develop forms of IVF that result in fewer discarded embryos. Moreover, because hESC research has the potential to benefit many more people than fetal tissue research and the moral status of early embryos is more controversial than that of older fetuses, restrictions on the use of embryos for research and therapies (including fertility treatment) might be more easily loosened than the abortion regulations that Gillam has in mind. Using discarded IVF embryos may also cause those already uncertain about the moral status of the embryo to feel increasingly comfortable about the use of embryos for beneficial research, and even about creating them for research!

Perhaps defenders of the discarded-created distinction are right that the use of discarded IVF embryos to obtain stem cells does not create a demand for discarded IVF embryos, but there is another way in which it might, indirectly, promote embryo destruction due to IVF: by altering our attitudes to it.

If embryos have significant moral status and it is true that one indirectly promotes embryo destruction by using discarded IVF embryos, it seems that something significant will be lost. 
Though it may be true that nothing-is-lost for the very embryos that the researchers in question destroy, doing the research may contribute to losses suffered by other embryos in the future.

According to the discarded-created distinction, a researcher using or deriving stem cells from a research embryo cannot appeal to the nothing-is-lost argument because he is partly responsible for the fact that the embryo was going to die anyway, or for the fact that some future embryo is going to die anyway. However, I have now argued that a similar result holds in the case of using and deriving stem cells from discarded IVF embryos. Even though it may be true that this research does not contribute to the unavoidable death of the embryos one destroys, it does contribute to the unavoidable death of future embryos, albeit via different mechanisms. In neither case, then, is the nothing-is-lost argument persuasive. Adherents of the discarded-created distinction must convincingly show that, although deriving stem cells from research embryos contributes to future embryo deaths, deriving stem cells from discarded IVF embryos does not. Unless they can do this, the nothing-is-lost argument cannot support the discarded-created distinction.

\section{A FINAL ATTEMPT TO SAVE THE DISCARDED-CREATED DISTINCTION}

\section{Using Research Embryos Contributes to a Greater Loss}

Perhaps there is another argument that can support the discarded-created distinction. Suppose we accept that both research on discarded IVF embryos and research on research embryos contribute to future losses; the former contributes to future IVF practices that result in many embryo deaths, and the latter to increased demand for, and thus further deaths of, research embryos. Still, it might be argued that the latter losses are more important than the former. Moreover, the difference in costs (so not the direct cost of deriving the stem cells but downstream costs of further embryo deaths) could be sufficient to ensure that the benefits of stem cell research outweigh the downstream costs of doing research on discarded IVF embryos, but do not outweigh the downstream costs of doing research on research embryos. This could be so, for example, if it is significantly worse that embryos die for research than for reproduction (as in IVF).

\section{Worse that embryos die for research than for reproduction}

Some have argued it must be significantly worse that embryos die for research than for reproduction, as in IVF. Two reasons could be advanced to support this claim: (1) research embryos are treated as a mere means whereas discarded IVF embryos are not (or not to the same degree), and (2) discarded IVF embryos die in the service of more important goods than do research embryos. Let us take a closer look at each of these arguments.

Research embryos are treated as mere means

It has been argued that by creating research embryos we treat the embryo as a mere means, thereby not handling it with the appropriate respect such a form of human life is entitled to. 
The underlying idea is that respect for human beings prevents the instrumental use of embryos, an act which according to some violates human dignity.[16]

However, embryos are used as a mere means in IVF too.[17] As mentioned earlier, IVF - as it is practised in most countries - involves the deliberate creation of many surplus embryos that will be discarded. The reason for creating such a surplus of embryos is not the hope that each of the embryos will develop into a baby. It is to spare women from further egg retrievals. Embryos created in IVF are thus mere means too.

In response to this observation it is often objected that IVF embryos are created with the primary intention to create a child. The principle of double effect is then invoked and it is argued that the fact that remaining IVF embryos are discarded on a large scale is merely an unintended side effect of IVF and therefore acceptable. However, it seems implausible to speak of a 'side effect' when we know that for every embryo transferred to the womb, another will be discarded (In the UK, for example, more than two million IVF embryos were created between 1991 and 2005, more than half of which were discarded [18]). In any case, even if creating surplus embryos is a side effect, it is not an unintended one. After all, IVF could be done without creating surplus embryos. In some countries IVF does not involve the creation of surplus embryos. Creating surplus embryos is not an unavoidable side effect of IVF. It is intentionally brought about in order to reduce harm to women undergoing IVF.

But if it the instrumentalisation of embryos to help reduce harm to women undergoing IVF is permissible, why, then, is the instrumentalisation of embryos for important biomedical research and for developing treatments for currently incurable diseases impermissible?

One possible reply is that IVF involves a different kind of instrumentalisation. At the time of creation, IVF embryos have a prospect of implantation, even if, once not selected for implantation, they will be discarded. Research embryos do not have this prospect. They are created for a purpose entirely external to themselves and are therefore used as mere means to a greater degree, or in a more problematic way.[19]

But is it really the case that having the prospect of further development makes a significant moral difference? This seems implausible. Consider the following scenario. Suppose we create research embryos but randomly select some of these embryos for donation to infertile couples. At the time of their creation, research embryos, just like IVF embryos, would have the prospect of developing into a baby. This would be true even if we donated only one embryo to an infertile couple. But this doesn't seem to treat the embryos with more respect. A better candidate for treating them with respect seems to be to restrict the use of embryos to important scientific research (like we do with cadavers or animal research). Note that only a minority of left over IVF embryos is donated for research; most left over embryos are just let to perish. If respect for the embryo is what is so important, it is not clear how contributing to letting IVF embryos perish on a large scale is more respectful than destroying embryos for, and only for, research that can save and improve many people's lives.

Discarded IVF embryos die in the service of more important goods 
Some people may argue that the goods produced by IVF are more important than the goods produced by using research embryos. Permissive attitudes to (and regulations regarding) the destructive use of embryos in the context of IVF have mostly been justified by reference to the right to reproductive liberty, which in turn has been justified by pointing to the central position of reproductive projects in people's lives. These justifications cannot be invoked to defend the use of embryos in the context of research.[20]

Although this is true, it seems implausible that protecting reproductive liberty and helping infertile people to realise their wish for a child produces more important goods than saving people's lives. After all, it is generally accepted that saving lives is more important than creating lives. It is also plausible that saving lives is more important than protecting reproductive liberty.

There are other reasons why the goods produced by IVF could be more important. One may argue that by not creating surplus embryos we harm women undergoing IVF, whereas by not creating research embryos we merely allow harm to occur to individuals in need of stem cell based therapies. Many believe that it is typically worse to do harm than to allow harm to occur. For example, many believe that it is typically wrong to kill a person even in circumstances in which it would be permissible to let that person die. However, although it may be true that not creating surplus embryos causes at least some of the harm to women undergoing IVF (as they may have to undergo hormone treatment several times), it is mainly the women's decision to proceed with IVF which harms them. Not creating surplus embryos can then be seen as 'merely' allowing harm to occur and consequently is, morally speaking, on a par with not creating research embryos. The 'doing versus allowing harm' distinction, insofar as it has any force in this context, cannot provide a ground for arguing that the goods produced by using discarded IVF embryos are greater than those produced by using research embryos.

To support the claim that creating surplus embryos in IVF produces more important goods one may also argue (1) that we should care more about current harms to present individuals than about future harms to them or (2) that we should give more weight to harm to current individuals than to future individuals. However, first of all, it seems implausible that mere location in time accords special significance to a benefit or harm. If my neighbour burns painted and glued wood in his chimney on a daily basis, and as a result of the poisonous smoke I get lung cancer, it shouldn't matter morally whether I get cancer now, or within 10 years. In both cases my neighbour should be stopped from burning treated wood now. Secondly, there does not seem to be a strong reason for an institution to treat the interests of future individuals any differently from those of present individuals either. Suppose the poisonous particles remain in the air for more than 20 years, and an individual that wasn't born at the time the burning took place now lives in my apartment and gets lung cancer as a result of the burning of treated wood 20 years ago. We have as much reason to stop my neighbour from burning now. After all, it is equally bad for the future person than for me to get lung cancer. The badness consists in getting the cancer, not in what generation it occurs (assuming the circumstances are similar).[21] Likewise, the fact that the women undergoing IVF exist now does not make the goods produced by killing embryos for IVF more important 
than the goods produced by killing embryos to prevent harm to future persons in need of stem cell-based treatments.

\section{CONCLUSION}

I started by investigating how proponents of the discarded-created distinction justify the destruction of discarded IVF embryos to obtain stem cells and showed that this justification also applies, at least at first sight, to the destruction of research embryos. This suggests that there should be a presumption against the discarded-created distinction. I then considered whether this presumption can be overridden. I concluded that the strongest arguments adduced in support of the discarded-created distinction do not hold. The nothing-is-lost argument fails. Whether one performs stem cell research using discarded IVF embryos or research embryos, one contributes to future embryo deaths and thus, something is lost. The argument that the moral (downstream) costs of the two types of stem cell research are sufficiently different that, in the one case they are outweighed by the benefits, but in the other they are not, does not hold either. In both IVF and embryo research, embryos are clearly treated as a mere means. Moreover, it is implausible that the goods created through IVF are more important than the goods created by experiments with research embryos. Saving lives is more important than creating lives, and both IVF and stem cell research aim to prevent harm. It doesn't matter whether this is current or future harm, or harm to existing or future people. It seems, then, that once one accepts the use and derivation of stem cells from discarded IVF embryos, it is hard to justify rejecting the use and derivation of stem cells from research embryos. Since there is, I have argued, a presumption against the discarded-created distinction, as long as no good argument has been adduced in support of the discarded-created distinction, we should reject it.

\section{REFERENCES}

[1] National Advisory Bioethics Commission (NBAC). (1999) Ethical Issues in Human Stem Cell Research, NBAC, Rockville, MD.

[2] Commission of the European Communities.(2003) Report on Human Embryonic Stem Cell Research, p.9. European Commission, Brussels.

[3] Fletcher JC. (2001) NBAC's arguments on embryo research: strengths and weaknesses. In: S Holland, K Lebacqz \& L Zoloth L (eds), The Human Embryonic Stem Cell Debate: Science, Ethics, and Public Policy, 61-72. MIT Press, Cambridge, MA.

[4] Pennings G, Van Steirteghem A. (2004) The subsidiarity principle in the context of embryonic stem cell research. Hum Reprod 19(5): 1060-4.

[5] McHugh PR. (2004) Zygote and "clonote": the ethical use of embryonic stem cells. N Engl f Med 351: 209-11.

[6] Outka G. (2009). The ethics of embryonic stem cell research and the principle of nothing is lost. Yale f Health Policy Ethics 9:585-602. 
[7] Ramsey P.(1961) War and the Christian Conscience: How Shall Modern War be Conducted fustly? Duke University Press, Durham, N.C.

[8] Williams B. (1973) A Critique of Utilitarianism. In Smart \& Williams, 'Utilitarianism: For and Against', Cambridge University Press, Cambridge, 1973.

[9] Prieur MR, Atkinson J, Hardingham L, et al. (2006) Stem cell research in a Catholic institution: yes or no? Kennedy Inst Ethics $\mathcal{F}$ 16(1):73-98.

[10] Zoloth L. (2002) Jordan's banks, a view from the first years of human embryonic stem cell research. Am f Bioethics 2: 3-11.

[11] Robertson JA. (2003). Causative vs. beneficial complicity in the embryonic stem cell debate. Conn L Rev 36: 1099-1113.

[12] Green RM. (2002). Benefiting from 'evil': an incipient moral problem in human stem cell research. Bioethics 16:544-56.

[13] Brock DW. (2010). Creating embryos for use in stem cell research. J Law Med Ethics 38(2):229-37.

[14] Gillam L. (1997) Arguing by analogy in the fetal tissue debate. Bioethics 11(5):397-412.

[15] Takala T, Häyry M. (2007) Benefiting from past wrongdoing, human embryonic stem cell lines, and the fragility of the German legal position. Bioethics 21(3):150-159.

[16] Heinemann T, Honnefelder L. (2002) Principles of ethical decision making regarding embryonic stem cell research in Germany. Bioethics 16:530-43.

[17] Savulescu J. (2004) Embryo research: are there any lessons from natural reproduction? Camb Q Healthc Ethics 13: 68-95.

[18] Woolf M. (Dec 30, 2007) IVF clinics destroy 1m 'waste' embryos. Available at: http://www.timesonline.co.uk/tol/life_and_style/health/article3108160.ece (last accessed 6 August 2010).

[19] The House of Lords, Stem Cell Research Committee.(2002) Stem Cell Research, Chapter 4, section 4.27. House of Lords, London.

[20] Holm S. (2003) The ethical case against stem cell research. Cambridge Quarterly of Healthcare Ethics 12(4): 372-83.

[21] Savulescu J. (2007). Future people, involuntary medical treatment in pregnancy and the duty of easy rescue. Utilitas 19(1):1-20. 